\title{
Research Article \\ Effect of Clay Addition on Mechanical Properties of Unsaturated Polyester/Glass Fiber Composites
}

\author{
Kusmono $^{1}$ and Zainal Arifin Mohd Ishak ${ }^{2}$ \\ ${ }^{1}$ Department of Mechanical and Industrial Engineering, Faculty of Engineering, Universitas Gadjah Mada, Jln. Grafika No. 2, \\ Yogyakarta 55281, Indonesia \\ ${ }^{2}$ School of Materials and Mineral Resources Engineering, Engineering Campus, Universiti Sains Malaysia, 14300 Nibong Tebal, \\ Penang, Malaysia \\ Correspondence should be addressed to Kusmono; kusmono72@yahoo.com
}

Received 5 June 2013; Accepted 8 October 2013

Academic Editor: Marek Cypryk

Copyright ( 2013 Kusmono and Z. Arifin Mohd Ishak. This is an open access article distributed under the Creative Commons Attribution License, which permits unrestricted use, distribution, and reproduction in any medium, provided the original work is properly cited.

\begin{abstract}
Unsaturated polyester (UP)/glass fiber/clay composites were prepared by hand layup method. The effect of clay loading on the morphological and mechanical properties of UP/glass fiber composites was investigated in this study. X-ray diffraction (XRD) was used to characterize the structure of the composites. The mechanical properties of the composites were determined by tensile, flexural, unnotched Charpy impact and fracture toughness tests. XRD results indicated that the exfoliated structure was found in the composite containing $2 \mathrm{wt} \%$ of clay while the intercalated structure was obtained in the composite with $6 \mathrm{wt} \%$ of clay. The tensile strength, flexural strength, and flexural modulus of the composites were increased in the presence of clay. The optimum loading of clay in the UP/glass fiber composites was attained at $2 \mathrm{wt} \%$, where the improvement in in tensile strength, flexural strength, and flexural modulus was approximately 13,21 , and $11 \%$, respectively. On the other hand, the highest values in impact toughness and fracture toughness were observed in the composites with $4 \mathrm{wt} \%$ of clay.
\end{abstract}

\section{Introduction}

Glass fiber reinforced composites have become attractive structural materials not only in weight sensitive aerospace industry but also in marine, armor, automobile, railways, civil engineering structures, sport goods, and so forth. This is attributed to high specific strength and specific stiffness of the glass fiber reinforced composites. Unsaturated polyester (UP) is one of most commonly used polymer matrix with reinforcing fibers for advanced composites applications due to its low cost, easy handling, rigid, resilient, flexible, corrosion resistant, weather resistant, and flame retardant.

Montmorillonite clay has received much attention as reinforcing materials for polymer because of its potentially high aspect ratio and unique intercalation/exfoliation characteristics. The small amount addition of montmorillonite clay into polymer matrix exhibits unexpected properties including reducing gas permeability, improved solvent resistance, being superior in mechanical properties and thermal stability, and enhanced flame retardant properties [1]. Typically, clay minerals have a layered silicate structure about $1 \mathrm{~nm}$ in thickness and high aspect ratio ranging from 100 to 1500 [2]. Glass fiber is a part of reinforcing materials for reinforced polymer based on single filaments of glass ranging in diameter from 3 to 19 micrometer. Glass fibers show good performance and play a main function in playground equipment, recreational items, piping for corrosive chemicals, and many other common applications. In addition, the cost of glass fiber is considerably lower than carbon fiber [3].

Polymer nanocomposites are new class of composites that are particle-filled polymers for which at least one dimension of the dispersed particles is in the nanometer range, that is, $1-100 \mathrm{~nm}$ [4]. Clay and carbon nanotubes are the most common used particles as reinforcement materials for polymer nanocomposites [1]. Polymer/clay nanocomposites (PCNs) are new class of composite materials, in which clay as layered silicate is dispersed in nanoscale size in a polymer matrix [4]. This interest stems from the fact that nanoclay filled 
polymers can exhibit dramatic improvements in mechanical and thermal properties at low clay contents because of the strong synergistic effects between the polymer and the silicate platelets of clay on both the molecular or nanometric. Studies on nanocomposites based on UP/clay have been done by previous researchers. Inceoglu and Yilmazer [5] reported that the tensile strength, tensile modulus, flexural strength, and flexural modulus of neat UP were improved by the presence of clay up to $5 \mathrm{wt} \%$. Above $5 \mathrm{wt} \%$ of clay, tensile and flexural properties were decreased. According to [6] Şen found that the exfoliation UP/clay nanocomposites exhibited better thermal and dynamic mechanical properties compared to the neat UP. Kornmann et al. [7] reported that tensile modulus and fracture toughness were increased with increasing the clay loading. However, being the brittle is a disadvantage property of nanocomposites which will limit their application. The addition of clay and glass fiber into neat UP was expected to develop high performance composites with high strength and toughness. A lot of studies can be found in the literature on the effect of addition of clay on the mechanical properties of pure UP resin systems. However, no investigation has been carried out on UP/glass fiber/clay composites.

Although numerous researchers investigated individually UP/glass fiber composites and UP/clay nanocomposites, no investigation has been carried out on UP/glass fiber/clay composites. The effect of clay loading on the morphological and mechanical properties of UP/glass fiber composites was investigated in this work. The mechanical properties of the UP/glass fiber/clay composites was determined through the mechanical testing such as tensile, flexural, impact, and fracture toughness tests. The dispersion of clay in the UP/glass fiber matrix was investigated by using $\mathrm{X}$-ray diffraction (XRD) and the SEN-3PB fracture surface of UP/glass fiber/clay composites was observed using scanning electron microscopy (SEM).

\section{Experimental}

2.1. Materials. UP (YUKALAC Type 157 BQTN-EX) was purchased from PT. Justus Kimiaraya, Semarang, Indonesia. The specific gravity of UP and viscosity are $1.10 \pm 0.02$ and 4.5-5.0 Poise $\left(25^{\circ} \mathrm{C}\right)$. Methyl ethyl ketone peroxide type A (MEPOXE) as catalyst was purchased from PT. Justus Kimiaraya, Semarang, Indonesia. The glass fiber used was in the form of chopped strand mat (CSM) and was provided from PT. Justus Kimiaraya, Semarang, Indonesia. The montmorillonite clay (Nanomer 1.28E), an organosilicate modified by quaternary trimethylstearylammonium ions having an approximate aspect ratio of 75-120, was purchased from Nanocor Co., USA.

2.2. Preparation of UP/Clay Composites. The clay was dried using an oven at $80^{\circ} \mathrm{C}$ for $6 \mathrm{~h}$ before being used. The UP/clay composites, with different clay loadings $(0,2,4$, and $6 \mathrm{wt} \%)$, were prepared by mixing the desired amount clay with UP resin using a mechanical stirrer at speed of $800 \mathrm{rpm}$ at $60^{\circ} \mathrm{C}$ for $2 \mathrm{~h}$. The MEXOPE catalyst was added into the UP/clay mixture by stoichiometric ratio. The mixture was then mixed using a mechanical stirrer and degassed in the vacuum oven. The UP/clay composites were then used as the matrix material of UP/glass fiber/clay composites.

2.3. Preparation of UP/Glass Fiber/Clay Composites. UP/clay/ glass fiber hybrid composites were prepared by hand layup method. Four plies $\left(20 \times 20 \mathrm{~cm}^{2}\right)$ of CSM were cut. A layer of UP/clay mixture was applied on a steel mold coated with a releasing agent of mirror glass. The first ply was laminated it became entirely wetted by the resin. Additional UP/clay mixture was added, and the second ply was laminated until complete wetting. This procedure was repeated until four plies were superimposed. Then, the sample was pressed with a metal roller to find the thickness of approximately $3.2 \mathrm{~mm}$. The composites samples were cured at $80^{\circ} \mathrm{C}$ for 3 hours. The cured composites were then cut into the proper geometry of specimens according to standards such as ASTM D638 type I standard for tensile, ASTM D790 for flexural, ASTM D 594296 for unnotched impact, and ASTM D 5045-96 for fracture toughness tests.

\subsection{Characterization and Mechanical Properties}

2.4.1. X-Ray Diffraction (XRD) Analysis. X-ray diffraction (XRD) measurements of the composites were carried out on bars. All these experiments were performed in reflection mode using X-ray diffractometer, Rigaku RINT2000, using $\mathrm{CuK} \alpha$ radiation at a scan rate of $0.3^{\circ} / \mathrm{min}$ in a $2 \theta$ range of $2-$ $10^{\circ}$, and operated at $40 \mathrm{kV}$ and $25 \mathrm{~mA}$.

\subsubsection{Mechanical Properties}

Tensile, Flexural, and Impact Tests. Tensile and flexural tests were performed using a universal testing machine (SERVO PULSER, Simadzu EFH-EB20-40L) at ambient temperature according to ASTM D638 type I and ASTM D790, respectively. Tensile test was performed at a crosshead speed of $10 \mathrm{~mm} / \mathrm{min}$. For flexural test, a three-point bending configuration was selected with a support span length of $50 \mathrm{~mm}$ and a crosshead speed of $10 \mathrm{~mm} / \mathrm{min}$. For flexural test, a threepoint bending configuration was selected with a support span length of $50 \mathrm{~mm}$. Impact test was carried out on unnotched specimens using a Pendulum Hammer Impact according to ASTM 256-02.

Fracture Toughness Test. Single-edge-notch 3-point-bending (SEN-3PB) test was conducted to obtain the critical stress intensity factor toughness $\left(K_{\mathrm{IC}}\right)$ of UP/glass fiber/clay composites according to ASTM D5045-96 standard using a universal testing machine (Torsee's). Rectangular specimens (thickness $6.35 \mathrm{~mm}$, width $12.70 \mathrm{~mm}$, span length $50 \mathrm{~mm}$, and overall length $56 \mathrm{~mm}$ ) were cut using a vertical band saw as shown in Figure 1. The notches were made first by the formation of saw-cut slots having rectangular shape with a width of $\sim 1 \mathrm{~mm}$ in the mid-section of specimens and then by sharpening with a fresh razor blade. The total notch length of SEN-3PB specimen was $6.5 \mathrm{~mm}$ deep. The fracture 


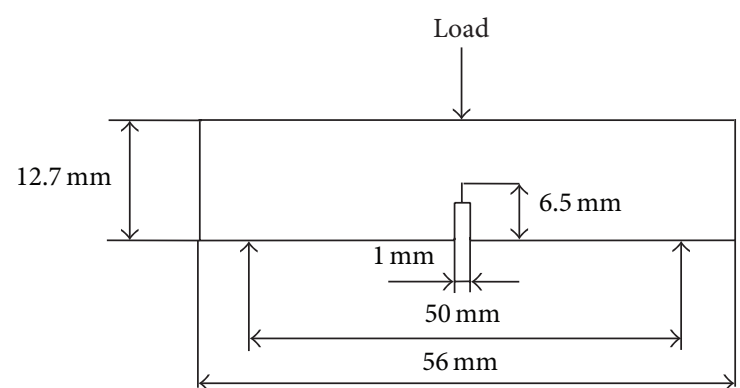

Figure 1: SEN-3PB specimen geometry used for the fracture toughness test.

toughness test was performed on a universal testing machine (SERVO PULSER, Simadzu EFH-EB20-40L) at crosshead speed of $10 \mathrm{~mm} / \mathrm{min}$. The load-displacement curves were recorded and the maximum loads upon fracture were used to determine the $K_{\mathrm{IC}}$ value, which is defined by [8]

$$
K_{\mathrm{IC}}=Y \frac{3 P S \sqrt{a}}{2 B W^{2}},
$$

where $Y$ is the shape factor, $P$ is the maximum load, $S$ is the length of the span, $B$ is the specimen thickness, $W$ is the specimen width, and $a$ is the total notch length (produced by saw and fresh razor blade). For specific specimen geometry, the shape factor can be determined by the following equation:

$$
\begin{aligned}
Y= & 1.93-3.07\left(\frac{a}{W}\right)+14.53\left(\frac{a}{W}\right)^{2} \\
& -25.11\left(\frac{a}{W}\right)^{3}+25.8\left(\frac{a}{W}\right)^{4} .
\end{aligned}
$$

2.4.3. Morphology Studies. The fracture surface of SEN-3PB specimens of UP/glass fiber/clay composites was investigated using scanning electron microscopy (JEOL SEM) at an acceleration voltage of $12 \mathrm{kV}$. The fracture surface was sputtercoated with a thin gold-palladium layer in vacuum chamber for conductivity before examination.

\section{Results and Discussion}

3.1. X-Ray Diffraction. Figure 2 shows the XRD patterns of clay, UP/glass fiber composite, and the composites containing 2 and $6 \mathrm{wt} \%$ of clay. For clay, the sharp peak at $2 \theta=3.54^{\circ}$ (dspacing $=2.49 \mathrm{~nm}$ ) is assigned to the (001) basal plane, which corresponds to an interlayer spacing of the clay. The absence of diffraction peak in the XRD pattern of the composite with $2 \mathrm{wt} \%$ of clay indicates the delamination and dispersion of the clay nanolayers within UP/glass fiber matrix, that is, the formation of an exfoliated structure [9]. On the other hand, the XRD pattern of the composite containing $6 \mathrm{wt} \%$ reveals the diffraction peaks at $2 \theta=4.52$ and $6.89^{\circ}$, corresponding to basal spacing of 1.95 and $1.28 \mathrm{~nm}$, respectively. The peaks observed in the composites with $6 \mathrm{wt} \%$ suggest the formation of intercalated structure and slash or agglomerated clay.

3.2. Mechanical Properties. Figure 3 shows the effect of clay loading on the tensile strength of the UP/glass fiber composites. It can be seen that an improvement of about $13 \%$

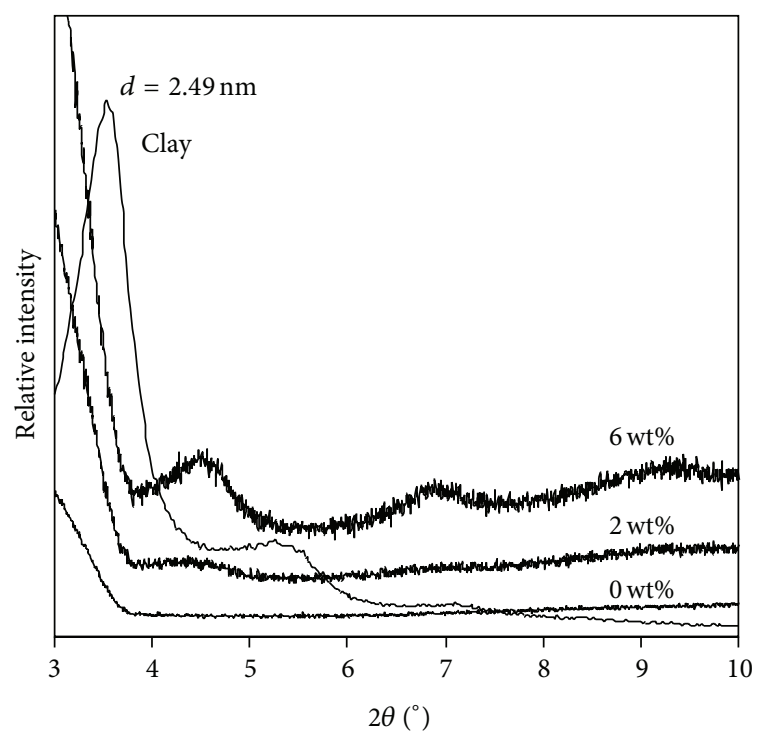

FIGURE 2: XRD patterns of the UP/glass fiber/clay nanocomposites with different clay loadings.

in the tensile strength was observed in the UP/glass fiber composite containing $2 \mathrm{wt} \%$ clay. The formation of exfoliated structure in the UP/glass fiber composite with $2 \mathrm{wt} \%$ clay as previously mentioned in the XRD results may be responsible for the improvement in the tensile strength. In the exfoliated structure, individually silicate layers in nanometer size are dispersed uniformly in the polymer matrix with high aspect ratio. The high aspect ratio of nanoclay may also increase the tensile strength by increasing the nanofiller contact surface with the polymer matrix. Large numbers of reinforcing nanoclay platelets presented in the polymer matrix act as efficient stress transfer agents in the nanocomposites [10]. In addition, the improvement in strength may be attributed to the reinforcing effect of the stiff clay particles. Furthermore, above $2 \mathrm{wt} \%$, the presence of clay drastically reduced the tensile strength of UP/glass fiber composites. This may be attributed to the intercalated structure in the nanocomposites with $2 \mathrm{wt} \%$ of clay loading. This structure leads to low aspect ratio of clay platelets and low contact surface area resulting in weak adhesion between polymer matrix and clay. This subsequently lowers their tensile strength. In addition, at high clay loading (above $2 \mathrm{wt} \%$ ), this behavior was probably attributed to the filler-filler interaction which resulted in agglomerates, induced local stress concentration, and finally reduced tensile strength of the nanocomposites [11, 12]. The clay agglomeration can be observed in Figure 8(b). A different result was reported by Bozkurt et al. [13] on epoxy/glass fiber/clay nanocomposites where the clay loading had a minor effect on the tensile properties.

The effect of clay loading on the flexural strength of UP/glass fiber/clay composites is shown in Figure 4. It is interesting to note that the flexural strength of UP/glass fiber composite was increased by $21 \%$ with the addition of $2 \mathrm{wt} \%$ of clay. Beyond $2 \mathrm{wt} \%$, the presence of clay in the UP/glass fiber composites has an opposite effect in flexural strength. This trend is similar to the tensile results in which the optimal 


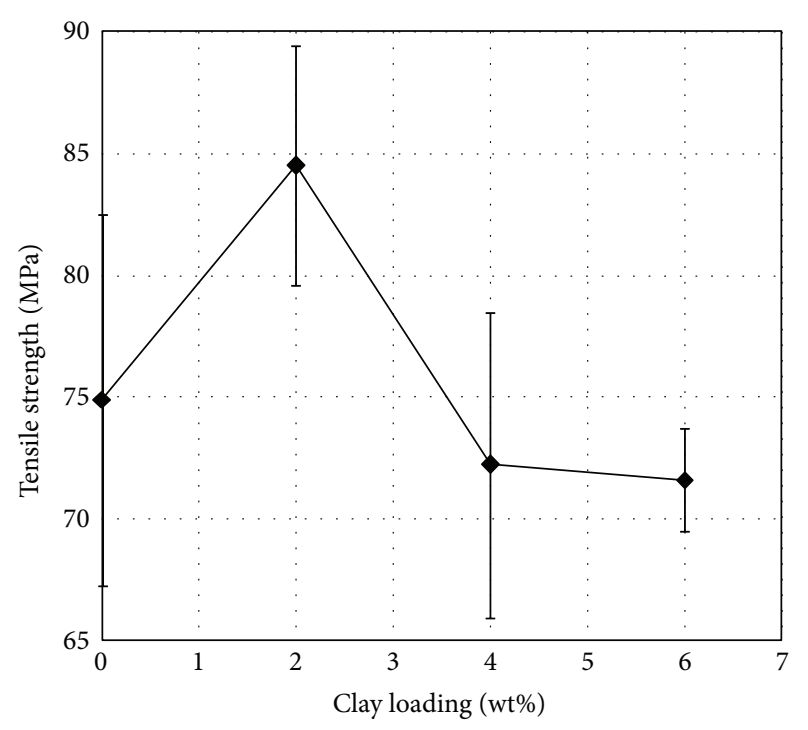

FIGURE 3: Effect of clay loading on the tensile strength of UP/glass fiber/clay composites.

clay loading was found at $2 \mathrm{wt} \%$ of clay. This may be related to the formation of exfoliated structure in the composite. In addition, the increment in flexural strength in the UP/glass fiber composites containing $2 \mathrm{wt} \%$ of clay may also be due to the presence of the silicate layers at the surface of the glass fiber, which may improve the interfacial interaction between UP matrix and glass fiber. Another possible cause could be the increment in the compression strength of the UP by the clay, thus improving the flexural strength of glass fiber reinforced UP composites [14]. The improvement in flexural strength in the fiber reinforced polymer composites containing clay was reported by several previous researchers. Kornmann et al. [14] and Manfredi et al. [15] demonstrated that the flexural strength of glass fiber reinforced epoxy composites was increased by the addition of clay. Norkhairunnisa et al. [16] reported that the optimum loading of clay in the epoxy/glass fiber composites was attained at $3 \mathrm{wt} \%$, where the improvement in flexural strength was $66 \%$. Furthermore, the decrease in flexural strength for above $2 \mathrm{wt} \%$ of clay may be due to the agglomeration of clay in the UP resin which acts as stress concentrators and leads to the reduction of flexural strength. $\mathrm{Xu}$ and Hoa [17] reported that the flexural strength was increased by $38 \%$ when 2 phr of clay was added into carbon fiber reinforced epoxy composites. Adding more $4 \mathrm{phr}$ of clay led to a drop in flexural strength due to poorer dispersion of nanoclay and more possibility of the existence of voids in composites.

Figure 5 presents the flexural modulus of UP/glass fiber/clay composites as function of clay loading. It was found that the optimal clay loading was obtained at $2 \mathrm{wt} \%$ where the flexural modulus of UP/glass fiber/clay composites was improved by $11 \%$. This may be attributed to the high modulus clay particles and to the strong interfacial interaction between the polymer matrix and clay as a result of the formation of exfoliated structure [18]. Intercalated structure and slash or agglomerated clay at more than $2 \mathrm{wt} \%$

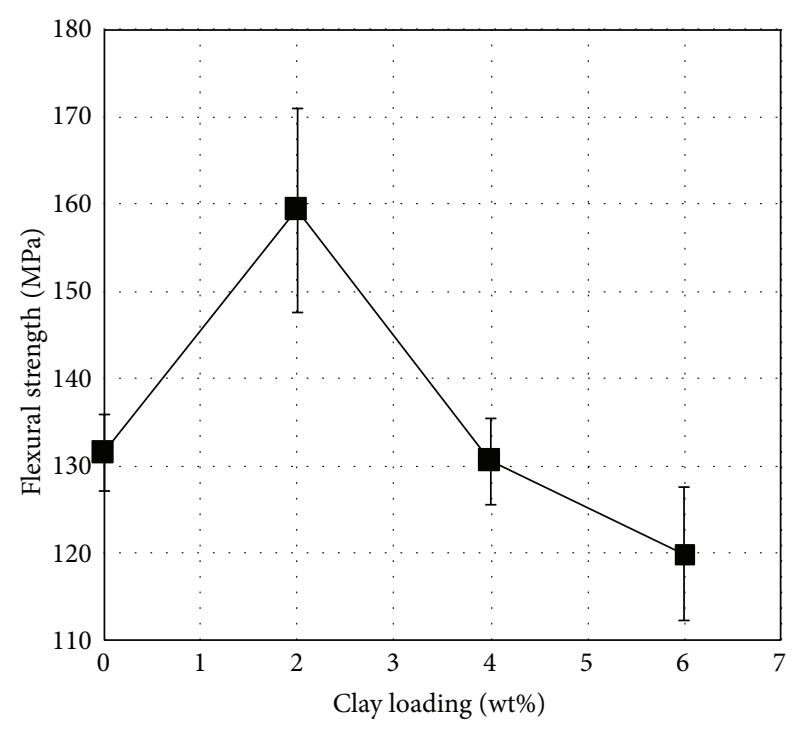

FIGURE 4: Effect of clay loading on the flexural strength of UP/glass fiber/clay composites.

of clay may be believed to be responsible for the decrease in flexural modulus. Similar observations were reported by Kornmann et al. [14], Norkhairunnisa et al. [16], and Manfredi et al. [15] on epoxy/glass fiber/clay composites. Kornmann et al. [14] reported that the addition of $10 \mathrm{wt} \%$ of clay into epoxy/glass fiber composites increased flexural modulus about $6 \%$. Norkhairunnisa et al. [16] found that the optimal loading of clay in the epoxy/glass fiber composites was attained at $3 \mathrm{wt} \%$, where the flexural modulus was increased by $95 \%$. Manfredi et al. [15] demonstrated that the addition of clay did not cause an increment in the flexural modulus of epoxy/glass fiber composites.

Figure 6 shows the effect of clay loading on the impact strength of UP/glass fiber/clay composites. It can be seen that the addition of clay up to $4 \mathrm{wt} \%$ significantly improved the impact strength. This suggests that the presence of clay up to $4 \mathrm{wt} \%$ increased the toughness of UP/glass fiber composites. The highest impact strength was found at $4 \mathrm{wt} \%$ where its improvement was $26 \%$. This may be related to the intercalated structure in the UP/glass fiber composite with $4 \mathrm{wt} \%$ of clay. In addition, in the intercalated structure, clay particles may form a tortuous fracture path [19] and the growth of microcrack is stopped by clay platelets [20,21]. On the other hand, in the exfoliated structure, the stronger the interface between polymer matrix and the fibers in the polymer composites can lower the impact strength [15]. Lin et al. [19] reported that the impact strength of epoxy/glass fiber/clay composites was increased with an increasing the clay loading for the impact direction was parallel to fiber orientation. Manfredi et al. [15] also presented that the presence of clay in the epoxy/glass fiber composites led to the improvement in toughness.

Figure 7 presents the effect of clay loading on the $K_{\text {IC }}$ values of UP/glass fiber/clay composites. It is well known that the $K_{\text {IC }}$ value indicates the fracture toughness of materials. From 


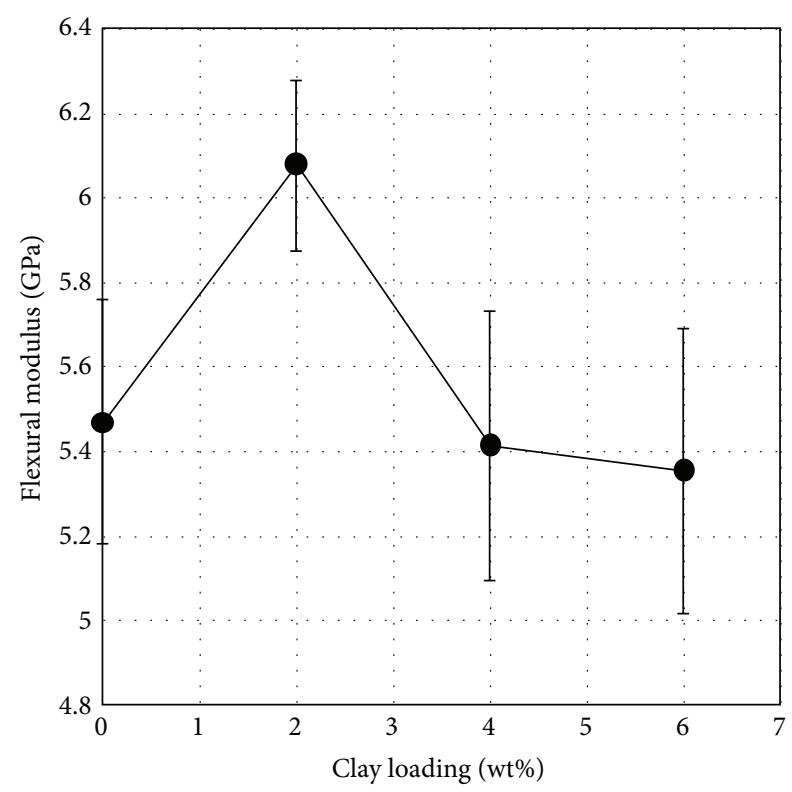

FIGURE 5: Effect of clay loading on the flexural modulus of UP/glass fiber/clay composites.

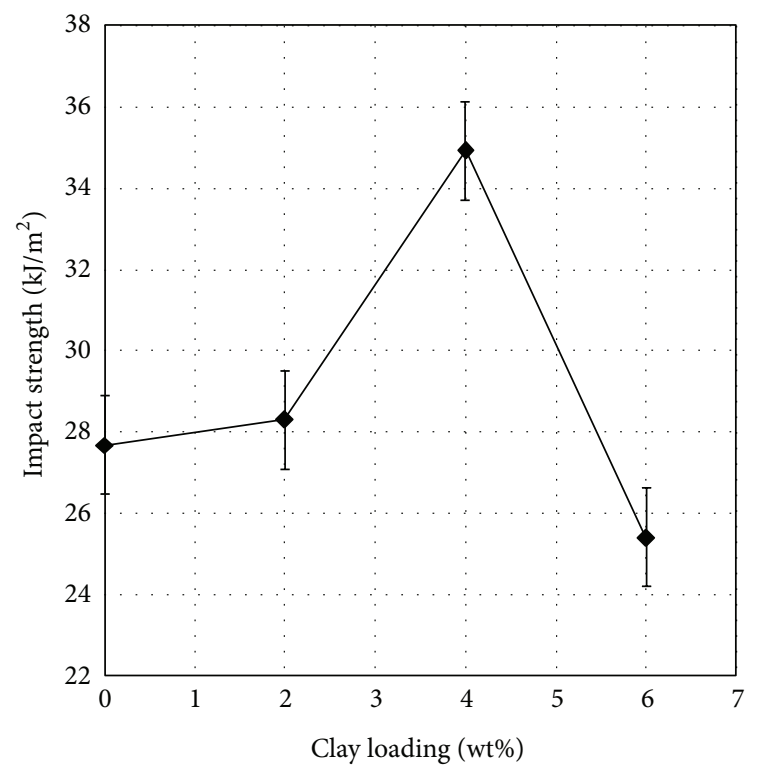

FIGURE 6: Effect of clay loading on the impact strength of UP/glass fiber/clay composites.

Figure 7, it can be seen that the $K_{\text {IC }}$ values of the composites were increased with an increase up to $4 \mathrm{wt} \%$ of clay loading. This trend is similar to the impact test results. The maximum improvement in fracture toughness was obtained at $4 \mathrm{wt} \%$ of clay loading and its improvement was $14 \%$. The improvement in fracture toughness may be related to the formation of the intercalated structures in the composite with $4 \mathrm{wt} \%$ of clay loading. On the other hand, the addition of $6 \mathrm{wt} \%$ of clay into the UP/glass fiber matrix reduced the $K_{\text {IC }}$ values. The reduction in $K_{\mathrm{IC}}$ values may be attributed to the higher amount of clay agglomerates [13]. Bozkurt et al. [13] studied

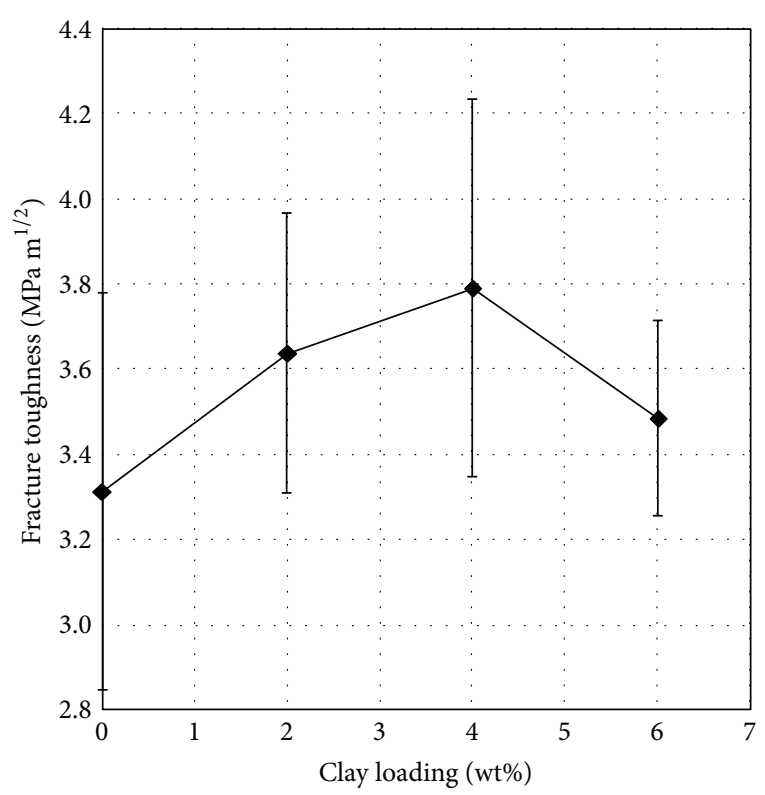

FIGURE 7: Effect of clay loading on the fracture toughness of UP/glass fiber/clay composites.

the properties of epoxy/glass fiber composites containing two different types of clay. The unmodified montmorillonite (MMT) and organomontmorillonite (OMMT) clay were used in the study. They found that the presence of MMT in the epoxy/glass fiber matrix slightly reduced the $K_{\text {IC }}$ values, and, on the other hand, the fracture toughness was increased by $5 \mathrm{wt} \%$ with the addition of OMMT. A better dispersion and intercalation of OMMT was believed to be responsible for this increase in $K_{\text {IC }}$ values. The improvement in fracture toughness with presence of clay in the epoxy/carbon fiber composites was reported by Dorigato et al. [22].

3.3. Morphology Studies. Figures 8(a) and 8(b) show the SEM micrographs of SEN-3PB fracture surface of the UP/glass fiber composite and UP/glass fiber composites containing $4 \mathrm{wt} \%$ of clay, respectively. From Figure $8(\mathrm{a})$, it can be seen that the UP/glass fiber composites exhibited a relatively smooth fracture surface especially on the UP matrix. Compared to the UP/glass fiber composite, the fracture surface of the UP/glass fiber/clay composites showed a much rougher fracture surface (as shown in Figure $8(\mathrm{~b})$ ). The very rough fracture surface is due to the presence of clay particles, which makes the fracture path more tortuous. This confirms a higher $K_{\text {IC }}$ value for the UP/glass fiber composite with $4 \mathrm{wt} \%$ of clay compared to the UP/glass fiber composite. It was concluded that the addition of clay into the UP/glass fiber composites has led to an increase in toughness. The toughening mechanism in the clay reinforced polymer composites may be attributed to the stress disturbance caused by the clay particles. These clay particles acted as obstacles, causing the crack to take a more tortuous part, manifesting a meandering crack trajectory. Therefore, these clay particles have a better resistance to crack propagation [9]. Moreover, a large number of agglomerates can be observed in SEM 


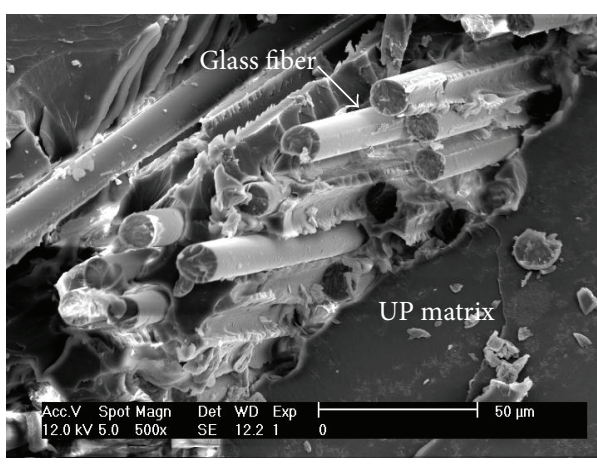

(a)

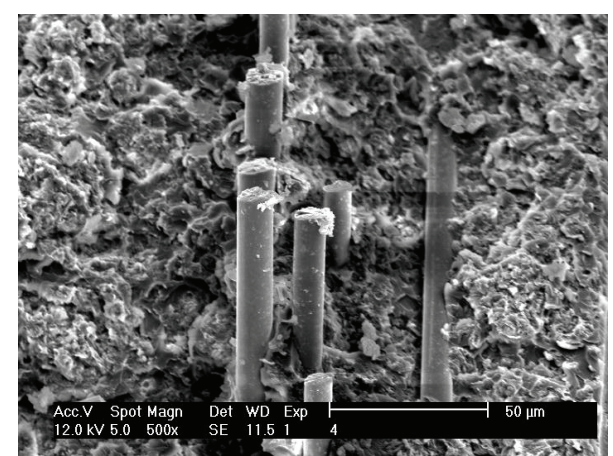

(b)

FIGURE 8: SEM micrographs of SEN-3PB fracture surface of (a) UP/glass fiber composites and (b) UP/glass fiber/clay composite with 4 wt\% of clay

micrograph of Figure 8(b), where such an observation can confirm the reduced mechanical performance at clay loading of $4 \%$ and above.

\section{Conclusion}

UP/glass fiber/clay composites were prepared by the hand layup method. XRD results indicated the formation of the exfoliated structure for the UP/glass fiber composite with $2 \mathrm{wt} \%$ of clay while the intercalated structure may be formed for the composite with $6 \mathrm{wt} \%$ of clay. Incorporation of clay into UP/glass fiber composites improved strength, stiffness, and toughness. The best properties in strength and stiffness were shown in the composites containing $2 \mathrm{wt} \%$ of clay while the best toughness was attained in the composites with $4 \mathrm{wt} \%$ of clay. The combination of clay and glass fiber had given a synergistic effect on the improvement in strength, stiffness, and toughness of UP matrix.

\section{Acknowledgments}

The financial support of Graduate Program of Mechanical Engineering Research Grant (Contract no. 1453/H1.17/ TMI/PL/2011), Faculty of Engineering, Universitas Gadjah Mada, is gratefully acknowledged. The authors also would like to thank Mr. Husaini for collecting the data.

\section{References}

[1] D. R. Paul and L. M. Robeson, "Polymer nanotechnology: nanocomposites," Polymer, vol. 49, no. 15, pp. 3187-3204, 2008.

[2] B. Guo, D. Jia, and C. Cai, "Effects of organo-montmorillonite dispersion on thermal stability of epoxy resin nanocomposites," European Polymer Journal, vol. 40, no. 8, pp. 1743-1748, 2004.

[3] M. W. Hyer, Stress Analysis of Fiber-Reinforced Composites Materials, McGraw-Hill, New York, NY, USA, 1998.

[4] M. Alexandre and P. Dubois, "Polymer-layered silicate nanocomposites: preparation, properties and uses of a new class of materials," Materials Science and Engineering R, vol. 28, no. 1-2, pp. 1-63, 2000.
[5] A. B. Inceoglu and U. Yilmazer, "Synthesis and mechanical properties of unsaturated polyester based nanocomposites," Polymer Engineering and Science, vol. 43, no. 3, pp. 661-669, 2003.

[6] S. Şen, "Effect of both silane-grafted and ion-exchanged organophilic clay in structural, thermal, and mechanical properties of unsaturated polyester nanocomposites," Polymer Composites, vol. 31, no. 3, pp. 482-490, 2010.

[7] X. Kornmann, L. A. Berglund, J. Sterte, and E. P. Giannelis, "Nanocomposites based on montmorillonite and unsaturated polyester," Polymer Engineering and Science, vol. 38, no. 8, pp. 1351-1358, 1998.

[8] R. W. Hertzberg, Deformation and Fracture Mechanics of Engineering Materials, John Wiley \& Sons, New York, NY, USA, 1989.

[9] T. Liu, W. C. Tjiu, Y. Tong, C. He, S. S. Goh, and T.-S. Chung, "Morphology and fracture behavior of intercalated epoxy/clay nanocomposites," Journal of Applied Polymer Science, vol. 94, no. 3, pp. 1236-1244, 2004.

[10] S. Parija, S. K. Nayak, S. K. Verma, and S. S. Tripathy, "Studies on physico-mechanical properties and thermal characteristics of polypropylene/layered silicate nanocomposites," Polymer Composites, vol. 25, no. 6, pp. 646-652, 2004.

[11] W. S. Chow, Z. A. M. Ishak, U. S. Ishiaku, J. Karger-Kocsis, and A. A. Apostolov, "The effect of organoclay on the mechanical properties and morphology of injection-molded polyamide 6/polypropylene nanocomposites," Journal of Applied Polymer Science, vol. 91, no. 1, pp. 175-189, 2004.

[12] S. Mohanty and S. K. Nayak, "Effect of clay exfoliation and organic modification on morphological, dynamic mechanical, and thermal behavior of melt-compounded polyamide- 6 nanocomposites," Polymer Composites, vol. 28, no. 2, pp. 153-162, 2007.

[13] E. Bozkurt, E. Kaya, and M. Tanoǧlu, "Mechanical and thermal behavior of non-crimp glass fiber reinforced layered clay/epoxy nanocomposites," Composites Science and Technology, vol. 67, no. 15-16, pp. 3394-3403, 2007.

[14] X. Kornmann, M. Rees, Y. Thomann, A. Necola, M. Barbezat, and R. Thomann, "Epoxy-layered silicate nanocomposites as matrix in glass fibre-reinforced composites," Composites Science and Technology, vol. 65, no. 14, pp. 2259-2268, 2005.

[15] L. B. Manfredi, H. de Santis, and A. Vázquez, "Influence of the addition of montmorillonite to the matrix of unidirectional glass fibre/epoxy composites on their mechanical and water absorption properties," Composites A, vol. 39, no. 11, pp. 17261731, 2008. 
[16] M. Norkhairunnisa, A. B. Azhar, and W. S. Chow, "Effects of organo-montmorillonite on the mechanical and morphological properties of epoxy/glass fiber composites," Polymer International, vol. 56, no. 4, pp. 512-517, 2007.

[17] Y. Xu and S. V. Hoa, "Mechanical properties of carbon fiber reinforced epoxy/clay nanocomposites," Composites Science and Technology, vol. 68, no. 3-4, pp. 854-861, 2008.

[18] S. S. Ray and M. Okamoto, "Polymer/layered silicate nanocomposites: a review from preparation to processing," Progress in Polymer Science, vol. 28, no. 11, pp. 1539-1641, 2003.

[19] J.-C. Lin, L. C. Chang, M. H. Nien, and H. L. Ho, "Mechanical behavior of various nanoparticle filled composites at lowvelocity impact," Composite Structures, vol. 74, no. 1, pp. 30-36, 2006.

[20] C. Basara, U. Yilmazer, and G. Bayram, "Synthesis and characterization of epoxy based nanocomposites," Journal of Applied Polymer Science, vol. 98, no. 3, pp. 1081-1086, 2005.

[21] A. J. Kinloch and A. C. Taylor, "Mechanical and fracture properties of epoxy/inorganic micro- and nano-composites," Journal of Materials Science Letters, vol. 22, no. 20, pp. 1439-1441, 2003.

[22] A. Dorigato, A. Pegoretti, and M. Quaresimin, "Thermo-mechanical characterization of epoxy/clay nanocomposites as matrices for carbon/nanoclay/epoxy laminates," Materials Science and Engineering A, vol. 528, no. 19-20, pp. 6324-6333, 2011. 

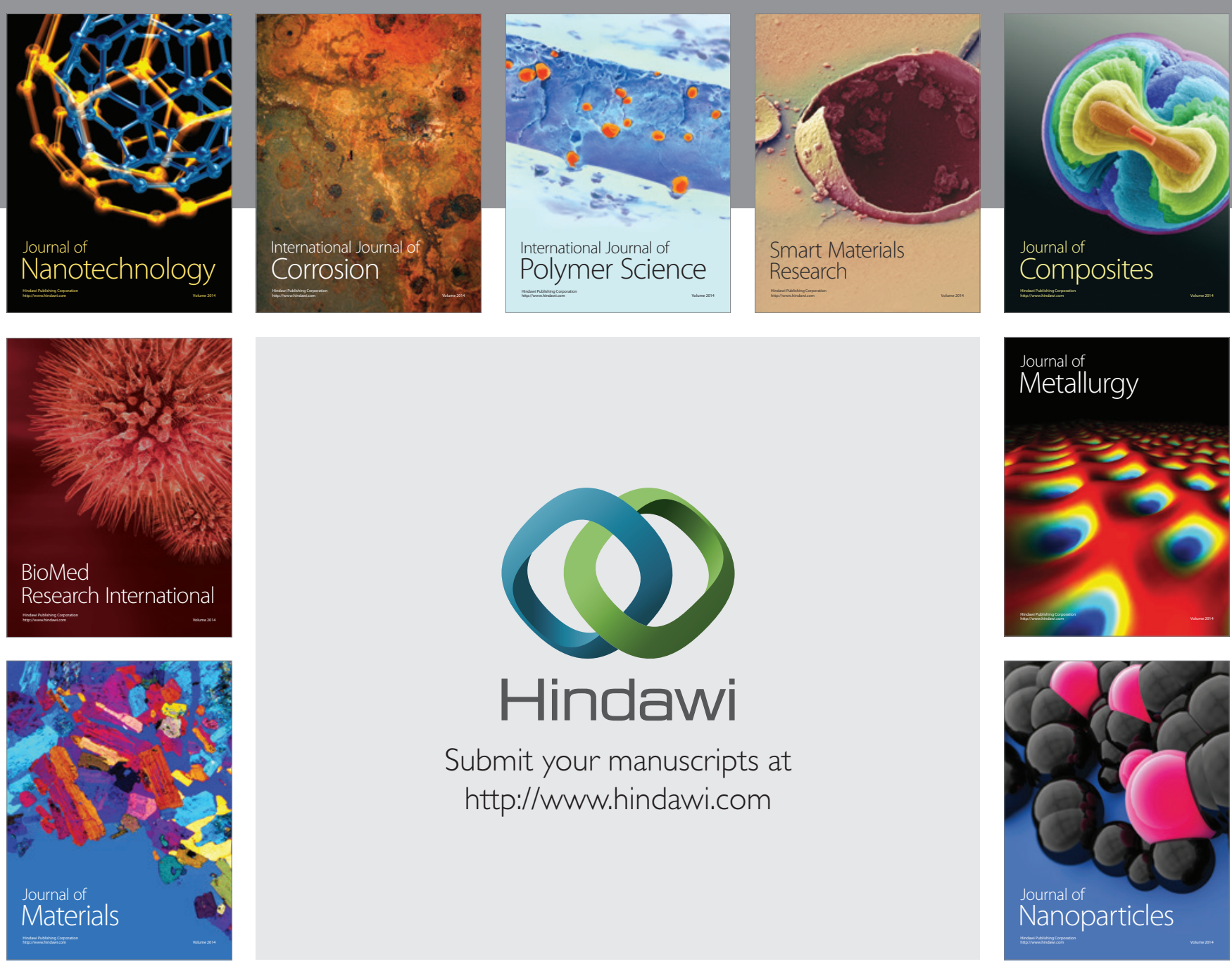

Submit your manuscripts at http://www.hindawi.com
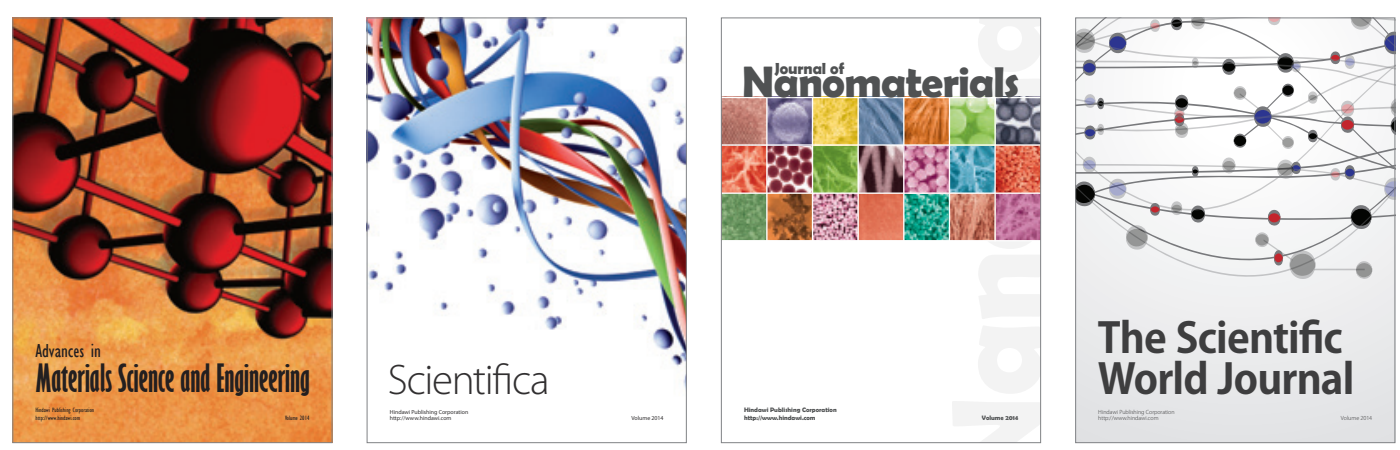

\section{The Scientific World Journal}
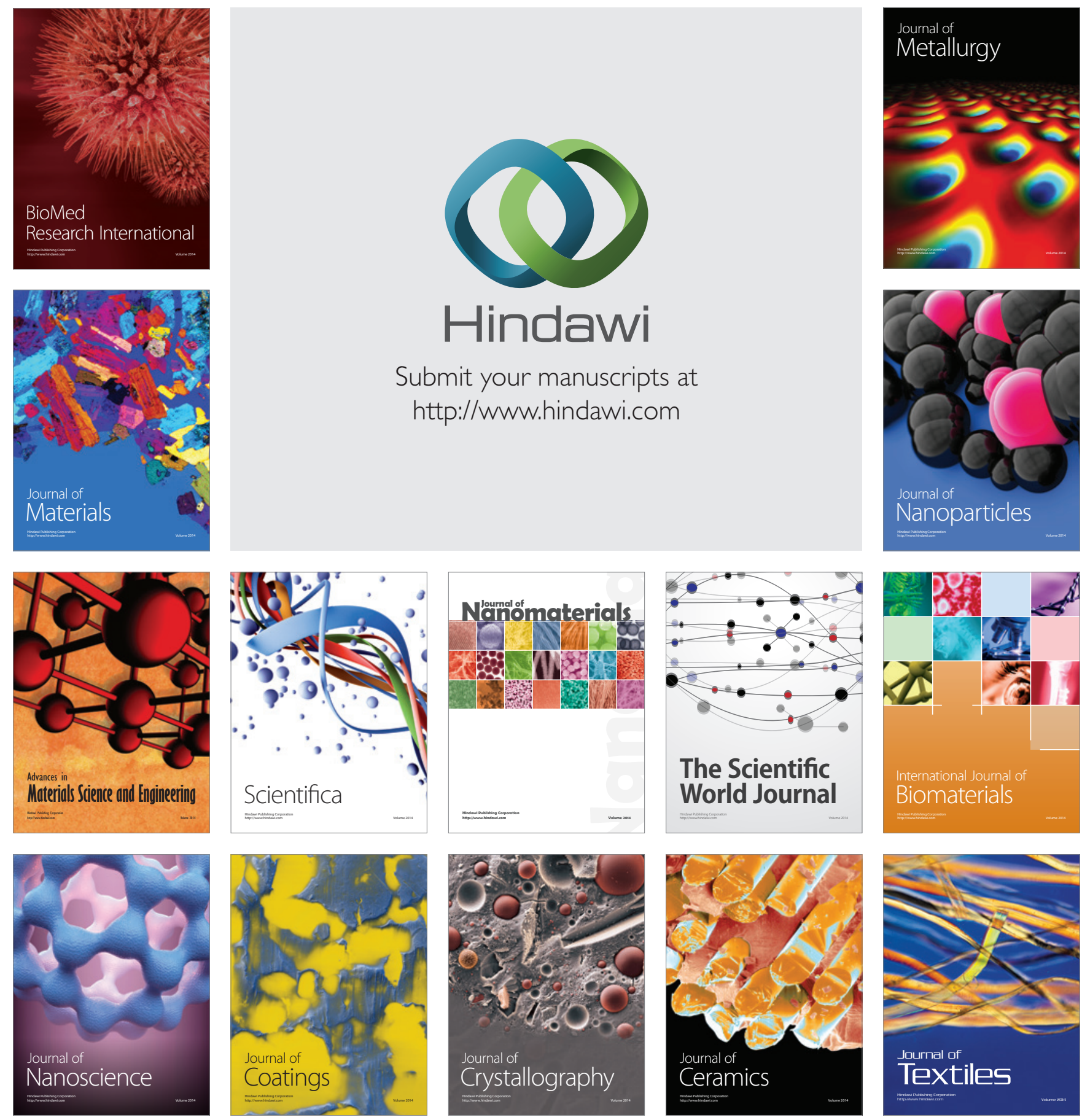